\title{
Study of Composite Plate Travelling in Water Containing Ice Equivalent Objects
}

\author{
Y. W. Kwon ${ }^{1 *}$, S. H. Bolstad ${ }^{1}$, J. M. Didoszak ${ }^{1}$, and J. A. Rodriguez ${ }^{2}$ \\ ${ }^{1}$ Dept. of Mechanical \& Aerospace Engineering \\ Naval Postgraduate School \\ Monterey, CA 93943, USA \\ ${ }^{2}$ Dept. of Ocean Engineering \\ US Naval Academy \\ Annapolis, Maryland 21402, USA
}

* Corresponding author (tel: 831-656-3468, e-mail: ywkwon@nps.edu) 


\begin{abstract}
An experimental study was conducted for a composite plate travelling in water containing ice equivalent objects (IEO) in order to investigate the drag force exerted on the composite plate as well as its structural response. This study considered both fluid-structure interaction (FSI) as well as solid body interaction. The plate was partially submerged so as to interact with the IEO. As test parameters, the travelling speed and the orientation angle of the plate were changed, and the coverage density of the IEO was also varied. Both drag force and the strain response of the plate were measured when the plate was in either the steady-state or accelerating transient motion. In addition, a high speed camera was utilized to capture the interaction among the composite plates, IEO, and water flow. Computer modeling and simulation was also conducted for some simple cases in order to better aid understanding. The results showed that with the inclusion of the IEO, not only was there an increase in the total drag forces but also a difference in the resulting deformed shapes of the plates. As a result, strain measurements at different locations did not vary proportionally resulting from the IEO.
\end{abstract}

Keyword: drag force, fluid-structure interaction, impact, ice 


\section{Introduction}

The emergence of more navigable sea lanes throughout the Arctic region is an on-going event due to changes in the extent of Arctic pack ice. This has resulted in heavier maritime traffic looking to capitalize on more efficient shipping routes between the northern Atlantic and Pacific Oceans. With this increase in the number of vessels transiting the Arctic sea routes, it is critical that ships be properly designed and designated to operate in the Arctic region.

There are several instances in which ships can interact with ice while transiting the Polar Regions. When pack ice or fast ice of sufficient thickness is encountered, ice-breakers are required for clearing a safe passage for transit. Such cases will not be addressed herein. On the other hand, when the sea is only partially frozen, ships can and do traverse the drift ice unaided, however at the peril of the surrounding ice pieces that may affect the traveling ships. This is precisely the topic considered in the study and especially with respect to composite structures.

Considerable research has been conducted on the interaction between traditional steel hulled ships and ice [1], while almost no research has been conducted for interaction between composite structures and ice to our best knowledge. Polymer composite structures exhibit much more significant fluid-structure interaction (FSI) than do metallic structures since the material densities of such composites are very comparable to that of water [2-6].

The use of composite materials continues to become more prevalent in naval ship design and construction. In 2006, the U.S. Navy launched an experimental vessel. The 27-meter long ship built of epoxy and carbon fiber is the Navy's first ship constructed entirely of composite materials and continues to serve as a ship capability demonstrator.

Another topic of interest covered in this study is the performance of different hull types as they travel thorough the water filled with drift ice. A ship hull is characterized not only by its 
profile but more importantly by the curvature of its sections as they pass through the design waterline. The three hull types under investigation are 1) the conventional or flared hull shape which has a negative angle of inclination with respect to the intersection of the beam at the design waterline, 2) the tumblehome hull which is found in the destroyer USS Zumwalt DDG1000 and possesses a positive angle, and 3) a ship hull with nearly vertical sides referred to as wall-sided, commonly found in tankers and cargo vessels, where the hull exhibits no inclination throughout its depth. Three different orientation angles of test plates used in the study to approximate these hull types are illustrated in Figure 1.

Because composite materials are typically found in the aviation industry, the bulk of research involving the impact resistance of composite materials stems from such applications [712]. The aviation industry is primarily concerned with two different types of impacts; highvelocity impacts which result in penetration of the composite and low-velocity impacts resulting in visual damage to the composite structure. Low-velocity impacts can result in matrix cracking, delamination, and fiber fracture.

While the previous research has not considered the FSI effect, other studies [2-5] showed that the FSI effect on composite structures submerged in water reduces the critical impact loads for failure as well as the number of cycles for failure to occur. In addition, FSI may change vibrational mode shapes, which can result in the shift of the critical failure location.

Hydrodynamic loading or drag force on a structure has also been an intensive research topic. However, most of the research studied a rigid structure by neglecting the structural flexibility [13-15]. Of interest, one study compared the drag forces applied to a polymer composite plate and a metallic plate with the same geometry [6]. Both plates were subjected to 
the same flow and boundary conditions. The results showed that the drag force was greater on the composite plate due to the FSI effect.

The objective of this research was to investigate the response of various hull types as they travel through the water and impact free-floating ice pieces. To this end, an experimental work was conducted inside a tow tank using Ice Equivalent Objects (IEO). Here IEO was used instead of actual ice since the tow tank was not located within a temperature controlled environment. Hence, the ice would have continued to melt and repeatable tow tank experiments would be difficult to complete in a meaningful manner. In addition, some computational fluid dynamic modeling and simulation was undertaken to enhance the understanding of the interaction between the representative test plates and the IEO.

The next section discusses the experiments conducted in this study. Then, two sets of test results are presented and discussed; the first is for the steady-state motion of the composite plate while the second is for the constant acceleration of the same plate. Then finally, conclusions are provided at the end. 


\section{Experiment}

\subsection{Experimental Set-up}

This experiment utilized a tow tank as shown in Figure 2 with its dimensions. In order to tow an object, a carriage attached to the top rails with ball bearings is suspending above the tank. This allows the carriage to translate along the length of the tow tank. The carriage is pulled using a motor that is speed controlled by adjustment of the input frequency in Hz. The relationship between the input frequency and the carriage velocity is linear as shown in Figure 3 . In order to avoid having the carriage strike the far side of the tow tank, the input speed is limited to10 $\mathrm{Hz}$. Testing at higher speeds would only be possible with a much longer tow tank.

In order to tow a composite plate at a specified angle through the water, an angle selector is located on the underside of the carriage, as is depicted in Figure 4. When the bottom edge of the composite plate is oriented toward the forward direction of the carriage motion, the angle setting is defined as positive. Otherwise, the angle is referred to as negative. At the zero position, that is when the plate is perpendicular to the primary direction of motion, there is no initial inclination of the plate.

A load cell is positioned on the front edge of the carriage. This load cell measures the force at which the pulley system tows the carriage. The other data obtained from this experiment was the strain experienced by the composite plate. The strain gauges were connected to quarterinch bridge adapters. These adapters and the load cell were connected to a National Instruments wireless sensor network which is capable of having four channels of experimental data streamed to a laptop using a Wi-Fi connection. The four channels were occupied by the three strain gauges on the plate and the carriage front load sensor. Data acquisition for the experiment was 
completed via a locally written module using the commercially available Labview software. The sampling rate for this experiment was set to100 samples per second.

The data for each trial can be divided into three stages, denoted here in Figure 5 as phases $\mathrm{A}, \mathrm{B}$ and $\mathrm{C}$. The first is the acceleration stage, termed phase A. In this stage, the force peaks rapidly as the pulley system begins to move the carriage from rest. The next stage, phase $\mathrm{B}$, is the steady state condition. At this point, the data is consistent and oscillates about an average value is observed. The last portion of the data record, phase $\mathrm{C}$, is the deceleration to stop the motion of the carriage.

\subsection{Composite Plate Fabrication}

The composite plate used in the tow tank experiment was fabricated using woven glass fabric, resin, and hardener. The plate has a free boundary as shown in Figure 6. The plate has no constraint along the boundary except for the test rig which was used to attach the test plate to the carriage of the tow tank. Strain gages were attached to the composite plate and were coated to make them waterproof. As shown in Figure 6, the locations at which the strain gages were attached was at the center and a quarter point of the plate. The center location has a strain gage oriented in the vertical direction while the quarter point location has both horizontal and vertical strain gages. The composite plate has overall dimensions of $0.3048 \mathrm{~m}$ x $0.3048 \mathrm{~m}$. It was constructed of ten layers, with a total thickness of $5.0 \mathrm{~mm}$. The layer-up was quasi-isotropic with an effective modulus of $20 \mathrm{GPa}$ and a density of $1475 \mathrm{Kg} / \mathrm{m}^{3}$. 


\subsection{Selection of Ice Equivalent Objects (IEO)}

In order to properly simulate Arctic ice, it is first necessary to have an understanding of the Arctic environment and the interaction between the ice and seawater. When seawater freezes, the salt and the water separate into two different phases called brine and ice. If salt is captured inside the body of the ice, it remains as a pocket of brine. Brine is a salt and water mixture with a very high concentration of salt. Hence any salt that is not physically contained within the ice dissolves back into the ocean [16]. This characteristic results in sea ice having a large range of density values. Numerous density measurements of sea ice have been compiled in [17]. The density of sea ice ranges from $720 \mathrm{~kg} / \mathrm{m}^{3}$ to $960 \mathrm{~kg} / \mathrm{m}^{3}$. Most recorded values are nearest to the upper limit of that range.

Having determined the density of sea ice, it was then necessary to find the density of Arctic Ocean water. The density of seawater is a function of its temperature and salinity according to the equation of state of seawater [18]. In order to obtain values for temperature and salinity, the National Oceanic and Atmospheric Administration (NOAA) database was used. The database requires the two inputs, time of season and water depth, in order to find the expected data for salinity and water temperature. Since Arctic sea lanes would be most accessible in spring and summer, those times were selected for use in this study. The surface layer was selected as the representative depth. Consequently, the data shows that the salinity varies from 29-35 PSU (Practical Salinity Unit) and the temperature varies from $-2^{\circ} \mathrm{C}$ to $6^{\circ} \mathrm{C}$. The maximum extreme of the density value results from the low temperature, high salinity water. The opposite combination results in the minimum extreme density value. Using the equation of state of seawater, the density of the Arctic seawater values ranged from $1022.8 \mathrm{~kg} / \mathrm{m}^{3}$ to $1028.2 \mathrm{~kg} / \mathrm{m}^{3}$. This results in a final density ratio of sea ice to Arctic Ocean seawater ranging between 0.70 and 0.94 . 
In order to obtain the correct floating behavior of the simulated ice in the fresh water tow tank, the density ratio between the ice and ocean water must match the simulated ice and the tow tank water. The fresh water in the tow tank had a density of $990 \mathrm{~kg} / \mathrm{m}^{3}$. This meant that the simulated ice must have a density ranging from $693 \mathrm{~kg} / \mathrm{m}^{3}$ to $931 \mathrm{~kg} / \mathrm{m}^{3}$. Because the upper limit is more probable, a material was selected close to that value.

Because the tests should be repeated for a period of time, using actual ice was not suitable in the tow tank at the room temperature, as predictably the ice would melt during the test. As a result, an ice equivalent material was sought. First and foremost, the selected material must be nonabsorbing, as absorption of water would change its density during testing. After considering cost, resistance to water absorption, and handiness, Low Density Polyethylene (LDPE) was chosen as the material to simulate ice. Cylindrical blocks of LDPE were used. The density of LPDE is $924 \mathrm{Kg} / \mathrm{m}^{3}$ resulting in a 0.933 density ratio of ice to water, which satisfies the requirement.

\subsection{Sizing of Ice Equivalent Objects (IEO)}

Two different scenarios were considered. The first scenario has two large size ice pieces floating in the water while the second scenario has a cluster of small ice pieces in the water. Consequently, two different sizes of LPDE rods were used. Two inch $(50.8 \mathrm{~mm})$ diameter rods were selected to simulate a field of small randomly dispersed sea ice masses, while larger four inch $(101.6 \mathrm{~mm})$ diameter rods were utilized to simulate impacts with large bodies of ice, as represented by the former case.

In order to have consistent floating characteristics, the rods were cut into various lengths and placed in the tow tank. The two inch $(50.8 \mathrm{~mm})$ diameter rod was cut into segments ranging 
from $25.4 \mathrm{~mm}$ to $63.5 \mathrm{~mm}$ at an increment of $12.7 \mathrm{~mm}$. The resulting floating characteristics of the rod segments are shown in Figure 7.

The $38.1 \mathrm{~mm}$ long segment was the longest section that exhibited the property of floating in an upward sense, that it with the centerline axis of the cylinder perpendicular to the waterline. As a result, all two inch $(50.8 \mathrm{~mm})$ diameter rods were cut into $38.1 \mathrm{~mm}$ long. Likewise, the larger four inch $(50.8 \mathrm{~mm})$ diameter rods were cut to a length of $76.2 \mathrm{~mm}$.

\subsection{Arrangements of Ice Equivalent Objects (IEO)}

This study simulated both small-size and large-size object collisions between a composite hull and free-floating ice. The small-size ice was represented by $38.1 \mathrm{~mm}$ long LDPE rod segments with a diameter of $50.8 \mathrm{~mm}$. The large-size ice was represented by $76.2 \mathrm{~mm}$ long LDPE rod segments with a diameter of $101.6 \mathrm{~mm}$. Multiple cases were considered.

The first case involves a large quantity of small pieces of ice. The two inch diameter rods were used to simulate this environment. To ensure repeatability between experiments, a specific surface coverage density of LDPE rods was used to determine how many rod sections should be placed in a section of the tow tank. The surface coverage density was calculated by dividing the product of the number of rods and the area of each rod by the maximum area of the rectangular section in the tow tank that could be occupied by the circular ice equivalent. The length of one glass panel of the tank determined the length of the area occupied by the ice equivalent. Each glass panel is $0.94 \mathrm{~m}$ long. The glass panel allows for the use of a high speed camera to observe flow characteristics and the interaction between the towed plate and the IEO. This experiment 
included low, medium and high ice surface coverage ratios as described in the next paragraph. The experimental set-up for two different surface coverage ratios is sketched in Figure 8.

The $0.94 \mathrm{~m}$ section of the tow tank was placed into three different groups. Each group contained 54 rods, which equated to a 0.125 ice surface coverage ratio for the tow tank segment. When all rods were added to the tow tank section, it was at the 0.375 surface coverage ratio. The rods were randomly distributed.

The second case simulated Arctic operating environment accounted for large free-floating ice that may be present in sea lanes. The goal was to model the impact between two large pieces of IEO with the composite hull. Two large pieces were placed in the tow tank as shown in Figure 9.

\subsection{Test Procedures}

To start, each composite plate is pulled in the tow tank without water being present. This test is used to measure the initial inertial force to move the carriage from the rest position without water effect. This value is subtracted from the force measured in water. Then, each plate was also tested in water without the introduction of IEO. This served as the base line to investigate the effect of the IEO in water.

Each composite plate was tested at three different orientation angles using the angle selector previously described in Figure 4 . The selected angles were $-30^{\circ}, 0^{\circ}$ and $+30^{\circ}$. In the following discussion, those plate orientations are called the negative, vertical, and positive angle, respectively. Then, different cases of IEO were also tested. Before each trial, the carriage was positioned near the left end of the tow tank. Ice equivalent blocks were placed in two locations, respectively. The first location was the section the plate would have the steady-state motion 
while the second location was the section the plate would have the accelerating transient motion. The speed of the plate was varied.

All trials for the various plate orientations were completed first for the lower ice coverage ratio. Time was allowed between successive trials for the tow tank water and LDPE rods to reach a state of rest. Upon the completion of the low ice coverage ratio testing, the additional LDPE segments required for higher ice density ratio were added to the tow tank.

Next, the four inch diameter LDPE segments were added to the tow tank. In order to ensure the LDPE segment remained in place, holes were drilled on side of each rod. Two rods were connected with a small length of soldering wire at the desired separation length. A length of thread was attached to the soldering wire. The thread was then connected to the pulley system, which was located along the centerline of the tow tank. Once the rods came to a state of rest at the center of the tank, the line was removed from the pulley system. The dangling thread was assumed to have a negligible effect on the experiment. The rod had to be manually placed for the off-centered single strike impact test. If the footage showed the rods moved out of location, the trial was repeated. The setup for the large ice impact tests is shown in Figure 9.

Once all of the experimental data was obtained, a water tight camera was attached to the bottom of the test plate. The camera was used to record underwater footage of the area immediately preceding the plate. The goal was to capture the interaction between the bow wave of various plate types and the ice equivalent in the plate's path. The composite plate with the camera is shown in Figure 10. 


\section{Results for Steady-State Motion}

Tests were repeated at least five times for each case. Then, the average value and standard deviation of each test case were computed. Figure 11 plots the average drag forces and the standard deviations for the plate at the different angles while the plate moves in water with or without IEO. The data shows that repeated test results did not show significant scattering, thus only the average values are presented in Figure 11, and subsequent figures so as not to overcrowd the plots.

\subsection{Base Water Test}

The plates were partially submerged in water. When the water in the tow tank was at rest, the top $12.7 \mathrm{~cm}$ of the composite plate was above the free water surface regardless of the orientation angle of the plate. The portion of the plate above the waterline is referred to as the "freeboard" going forward.

The composite plate was tested at three different orientations and various steady-state speeds in water without IEO. These results showed that it required a significantly less amount of force to move the negatively oriented plate (i.e., at $-30^{\circ}$ angle) through the tow tank as compared to the other two plate orientations. The positively oriented plate had the largest the drag force. Figure 11 shows the comparison for the base water trials without IEO.

The disparity in the drag forces most likely stems from the flow characteristics of the water around each plate orientation. The negatively oriented plate deflects the water down, whereas the positively oriented plate deflects the water up. This creates a large wave in front of the positively oriented plate, much like a ship's bow wave. The water also rises higher on the positively oriented plate as it travels faster through the water resulting in little to no freeboard. 
As the plate velocity increased, the water partially topped the positively oriented plate, which results in the plate having to displace more water and increasing the drag force. On the other hand, most of the initial freeboard above the waterline remained dry as the negatively oriented plate was towed through the water. The vertical plate exhibited the middle ground between the two other plates. Figure 12 displays the results from the computational fluid dynamics. The results also confirmed that the plate with the positive angle had a higher water level in front of the plate than the negatively angled plate. This resulted in a greater drag force for the former case.

Figure 13 illustrates the change of the drag force as a function of the steady-state velocity of the plate at different angles. Because the theoretical drag force varies quadratically as a function of the velocity, the experimental drag force also showed nonlinearity with the velocity. Among the three different angles, the vertical plate displayed the largest incremental change in drag force, changing from $1.50 \mathrm{~m} / \mathrm{s}$ to $1.67 \mathrm{~m} / \mathrm{s}$.

The vertical strain at the plate center is shown in Figure 14 for different plate angles as well as various steady-state velocities. The strain values in Figure 14 reflect the trend in the drag force presented in Figure 13. In other words, the plate with a negative angle has lower strains while the plate with the positive angle reveals higher strains. However, one thing to be noted is the fact that the strain at the negatively angled plate varies little with the plate velocity. The reason for this is that the deformed shape of the plate was not the same for different orientation angles and did not remain the same as the plate velocity increased. Figure 15 compares the pressure applied to the positively and negatively oriented plates, respectively. These were obtained from a computer simulation with $1 \mathrm{~m} / \mathrm{s}$ flow velocity. Because of the different pressure loading, the deformation shape is different for each angled plate. 


\subsection{Covered with Small Ice Equivalent Objects (IEO)}

The first case considered was that with $37.5 \%$ ice coverage using smaller rods as sketched in Figure 8. Ice equivalent objects floating in the water increased the drag force on the composite structure regardless of its orientation angle, as is shown in Figure 11. Because of the random distribution of the objects, there was a slightly larger standard deviation with the IEO compared to the base water case. Figure 13 compares the drag forces under different speeds. The negatively angled plate shows gradual increase in the drag force associated with the IEO as the plate speed increases. However, the other two angled plates show that the increase in the drag force is random with the IEO as the plate speed increases. Those results were related to how each plate interacted with the IEO.

Figure 16 compares the three differently oriented plates as they are in contact with the IEO. The arrows in the figure show the movement direction of the IEO after contact with the plate. While the plate is positioned in the negative angle orientation, the IEO moves down along the plate. On the other hand, the IEO moves up along the positively oriented plate. The vertical plate shows neither of those.

The computational model provides some clues why the IEO move in different directions for the negative and positive angled plate orientations. The peak fluid pressure measured above hydrostatic pressure is listed in Table 1 as a function of the depth from the free water surface. The fluid pressure preceding the positively oriented plate was consistently greater than the pressure in front of the negatively oriented plate. The negative plate shows a decrease in pressure along the depth while the positive plate shows an initial increase of pressure with increasing 
water depth. This increase in pressure may be the source of the ice displacement property exhibited by the positively oriented plate in the experiment.

Because the major contact area between the plate and IEO was different depending on the orientation angle of the plate, the resultant bending strains in the plates were also quite different. The changes in vertical strain at both the central and quarter point locations were relatively small but the change in the horizontal strain at the quarter point location was much larger due to the IEO in the water as shown in Figure 17. This suggests that the IEO produced larger bending of the plate about the vertical axis rather than about the horizontal axis. The change in the horizontal bending strain does not show any trend but rather is considered to be random as the plate speed also changes with different orientation angles. In other words, the deformed shapes of the plate did not remain the same as the plate speed increased. As a result, a higher plate speed with the IEO did not necessarily result in larger strain values at the same location.

The experiment showed that different IEO surface coverage ratios did not have a large effect on the drag forces and bending strains. The difference was within a couple percent. Again, the horizontal strain at the quarter point location had the largest difference as before.

\subsection{Covered with Large Ice Equivalent Objects (IEO)}

In this study, two large pieces of IEO were placed in water, which would impact the composite plate as it travelled. The percent change in the peak drag force and strains for the plate speed of $1.17 \mathrm{~m} / \mathrm{s}$ is tabulated in Table 2. The increase in force was greatest for the negatively oriented plate. The bow wave was not large enough to begin displacing the IEO. This would have softened the impact between the plate and the IEO. 
The results in Table 2 are best explained by inspecting the still images taken during the large ice trials. These images show that the relationship between the different plate orientations and the resulting behavior of the larger IEO are similar to those of the smaller IEO tests. The only difference between the two is that the larger rods have more inertia. This increase in inertia lessens the pushing effect of the "bow" wave preceding the plate.

The negatively oriented plate deflected the IEO deeper into the water, whereas the IEO moved with the positively oriented plate. The IEO also remained in front of the vertically oriented plate. The ice equivalent continued to travel in front of the plate for the vertical and positively oriented plates. The interaction between the IEO and the plate in these orientations was prolonged. This resulted in a low force impact for a long length of time. On the other hand, the conventional orientation resulted in a nearly instant, high force impact. 


\section{Results for Accelerating Motion}

These tests were also repeated at least five times for each case. Then, the average value and standard deviation of each test case were computed as plotted in Figure 18. The standard deviations were similar to those at the steady-state tests. As a result, the average values are presented in the following presentation to avoid over-crowdedness.

\subsection{Base Water Test}

The plate movement during the accelerating phase was measured using a high speed camera, and the velocity and acceleration were computed from the displacement. The displacement increased almost quadratically in terms of time during the acceleration phase before reaching the steady-state. Therefore, the acceleration was considered constant during this phase. The average measured acceleration was around $3.2 \mathrm{~m} / \mathrm{s}^{2}$ before reaching the steady-state velocity $1.50 \mathrm{~m} / \mathrm{s}$. As a result, the present data in acceleration are compared to the steady-state data with $1.50 \mathrm{~m} / \mathrm{s}$.

Figure 18 compares the drag forces with three different plate orientations under accelerating motion. The force results are similar qualitatively between the steady-state and accelerating motions. In other words, the negative orientation yielded the lowest drag force while the positive angle produced the largest force. However, the magnitude of the drag force was greater for the accelerating motion. When the accelerating motion was compared to the steadystate motion, the vertical plate showed an approximately $30 \%$ increase, the negative angle had a $50 \%$ increase, and the positive angle had a $15 \%$ increase.

The vertical strains at the plate center are plotted in Figure 19 for the three different plate orientations. As expected, a larger drag force results in a larger strain at the center location of the 
plate. However, the ratio of the strain per drag force is not constant because the deformed shape resulting from the drag force is not the same for the three different plate angles.

\subsection{Covered with Small Ice Equivalent Objects (IEO)}

The next study included the introduction of the IEO during the acceleration phase. The IEO were placed such that there were located in the area where plate was accelerating. Figures 18 and 19 compare the forces and strains with and without the IEO. While the vertical plate has the largest net increase in force, the negatively angled plate shows the greatest percent increase relative to the force without the IEO as seen in Figure 18. Comparing Figures 11 and 18 shows that the net increase in the force resulting from the IEO is larger during the acceleration phase than when the plate is in steady-state motion.

On the other hand, the vertical strain at the plate center shows small changes due to the IEO. As in the steady-state motion case, the IEO changed the deflection shape of the plate. Therefore, the largest change in strain occurs in the horizontal strain at the quarter point location of the plate out of three measured strains. Because the accelerating phase occurred before reaching the steady-state velocity of $1.50 \mathrm{~m} / \mathrm{s}$, Figure 20 can be compared to the plot for $1.50 \mathrm{~m} / \mathrm{s}$ in Figure 17. The change in the quarter point horizontal strain due to the introduction of the IEO is smaller for the accelerating motion. This suggests again that the plate deformation shape keeps changing as a result of the IEO. If the deformation shape were to remains the constant, the strains would be proportional to the force at every measured location. 


\section{Conclusions}

Both drag force and strain were measured for a partially submerged composite plate traveling through a fresh water tow tank at three different angles of orientation. Ice Equivalent Objects were added to the tow tank to simulate forward motion of a ship hull passing through drift ice. Both steady-state and constant acceleration motions were examined. The negatively oriented plate had the lowest drag force while the positively angled plate had the greatest drag force. The drag forces increased resulting from the presence of the IEO, an increase of steadystate speed, and accelerating velocity. However, the magnitude of such increases depended on the plate orientation angle and plate velocity. There was no consistency so as to predict the net increase, as the behavior was found to be of a random nature. One of the reasons for this was due to the flow characteristics over the plate depending on its orientation angle. The IEO was displaced downward in the case of the negatively angled plate while it was opposite for the positively oriented plate, while the vertically oriented plate proved to be the neutral case. These observations were consistent regardless of the size and coverage density of the IEO and were independent of the plate velocity. Such different flow characteristics resulted in different pressure distributions on the plate from the fluid as well as the IEO impacts. Additionally, different pressure distributions yielded different deformation of the plate as well as different FSI effects.

These facts complicated the interpretation of the bending strain responses. The effect resulting from the presence of the IEO was quite different on strain values measured at different locations and different plate orientations. The deformed shapes did not remain the same with the IEO impact even for the same plate orientation. Some locations and/or orientations had increases in strain due to the IEO while other locations showed a decrease. Thus, those changes were quite 
difficult to predict. However, for the present composite plate, it was found that the IEO influenced the horizontal strain significantly.

Different coverage densities of the IEO showed a small effect, which may be neglected in a practical sense, while the size of the ice pieces did make some appreciable difference in the structural response of the plate. In conclusion, the presence of floating ice should be considered in the design of a ship hull operating in the Arctic region when composite materials are to be used. In addition, the optimal hull orientation angle should be selected considering all the design requirements.

\section{Acknowledgment}

This work was supported by the Office of Naval Research, Solid Mechanics Program. The program manager is Dr. Yapa D. S. Rajapakse. 


\section{References}

[1] B. Leira, L. Børsheim, Ø. Espeland and J. Amdahl. Ice-load estimation for a ship hull based on continuous response monitoring. Proceedings of the Institution of Mechanical Engineers 223pp. 529-540. 2009.

[2] Y. W. Kwon, M. A. Violette, R. D. McCrillis, and J. M. Didoszak, "Transient Dynamic Response and Failure of Sandwich Composite Structures under Impact Loading with Fluid Structure Interaction", Applied Composite Materials., Vol. 19, No. 6, 2012, pp. 921-940.

[3] Y. W. Kwon, E. M. Priest and J. H. Gordis, "Investigation of Vibrational Characteristics of Composite Beams with Fluid-Structure Interaction”, Composite Structures, Vol. 105, November 2013, pp. 269-278.

[4] Y. W. Kwon, "Dynamic Responses of Composite Structures in Contact with Water While Subjected to Harmonic Loads", Applied Composite Materials, Vol. 21, 2014, pp. 227245.

[5] Y. W. Kwon and S. D. Plessas, "Numerical Modal Analysis of Composite Structures Coupled with Water", Composite Structures, Vol. 116, 2014, pp. 325-335.

[6] Y. W. Kwon, S C. Millhouse, and S. Arceneux, "Study of Composite Plate in Water with Transient and Steady Sate Motions", Composite Structures, Vol. 123, May 2015, 2015, pp. 393-400.

[7] Z. Aslan, R. Karakuzu, B. Okutan, "The Response of Laminated Composite Plates Under Low-Velocity Impact Loading," Composites Structures, vol. 59, pp. 119-127, 2003.

[8] Y. W. Kwon and G. W. Wojcik, "Impact Study of Sandwich Composite Structures with Delamination", Journal of Composite Materials, Vol. 32, No. 5, 1998, pp. 407-430. 
[9] J. N. Baucom and M. A. Zikry, "Low Velocity Impact Damage Progression in Woven EGlass Composite Systems", Composites Part A: Applied Science and Manufacturing, Vol. 36, No. 5, May 2005, pp. 658-664.

[10] R. A. W. Mines, C. M. Worrall, A. G. Gibson, "Low Velocity Perforation Behaviour of Polymer Composite Sandwich Panels", Int. Journal of Impact Engineering, Vol. 21, Issue 10, Nov. 1998, pp. 855-879.

[11] M. F. Pinnell and P. O. Sjoblom, "Low-Velocity Impact Testing of Thermoplastic and Thermoset Matrix Composite Materials," Wright Research and Development Center Air Force Systems Command, Wright-Patterson AFB., OH, Tech. Rep. 91-00898, Nov. 1990.

[12] W. Elber, "Failure Mechanics in Low-Velocity Impacts on Thin Composite Plates," Langley Research Center, Hampton, VA, Tech. Rep. 19951226 108, May 1983.

[13] Lund, K. O., "Low Reynolds-number moment on asymmetric bodies", Experimental Thermal and Fluid Science, Vol. 24, Issue 1-2, March 2001, pp. 61-66.

[14] Bagnold, R. A., "Experiments on a gravity-free dispersion of large solid spheres in a Newtonian fluid under shear", Proc. Royal Society London A, Vol. 225, No. 1160, August 1954, pp. 49-63.

[15] Kurose, R. and Komori, S., "Drag and lift forces on a rotating sphere in a linear shear flow", J. Fluid Mech., Vol. 384, 1999, pp. 183-206.

[16] P. Wadhams. (2003, January 01) How Does Arctic Sea Ice Form and Decay [Online]. Available: http://www.arctic.noaa.gov/essay_wadhams.html. 
[17] Frederking and Timco G. W. Timco and R. M. W. Frederking, "A Review of Sea Ice Density," National Research Council of Canada, Ottawa Canada, Tech. Rep. Mar. 1995.

[18] National Institute of Ocean Technology. Equation of State [Online]. Available: https://www.niot.res.in/COAT/coat_pdf/CHAP\%20III\%20$\% 20$ Equation\%20of\%20State.pdf. 
Table 1. Comparison of peak fluid pressures above the hydrostatic pressure preceding the plates

\begin{tabular}{|c|c|c|}
\hline $\begin{array}{c}\text { Depth from free } \\
\text { surface }(\mathrm{cm})\end{array}$ & $\begin{array}{c}\text { Pressure in front of } \\
\text { positively oriented plate }(\mathrm{Pa})\end{array}$ & $\begin{array}{c}\text { Pressure in front of negatively } \\
\text { oriented plate }(\mathrm{Pa})\end{array}$ \\
\hline 0 & 518.9 & 454.5 \\
\hline 7 & 518.9 & 408.0 \\
\hline 14 & 560.3 & 278.6 \\
\hline 21 & 164.0 & 107.6 \\
\hline
\end{tabular}

Table 2. Percent change for peak force and peak strain values at $1.17 \mathrm{~m} / \mathrm{s}$ due to impact with a single large IEO

\begin{tabular}{|c|c|c|c|c|}
\hline Orientation & Force & $\begin{array}{c}\text { Vertical Strain at } \\
\text { Quarter Location }\end{array}$ & $\begin{array}{c}\text { Horizontal Strain at } \\
\text { Quarter Location }\end{array}$ & $\begin{array}{c}\text { Vertical Strain at } \\
\text { Center }\end{array}$ \\
\hline Vertical & $6.68 \%$ & $-25.00 \%$ & $140.00 \%$ & $-11.84 \%$ \\
\hline$-30^{\circ}$ & $42.70 \%$ & $-41.67 \%$ & $85.71 \%$ & $-16.95 \%$ \\
\hline $30^{\circ}$ & $15.01 \%$ & $16.00 \%$ & $100.00 \%$ & $-8.60 \%$ \\
\hline
\end{tabular}




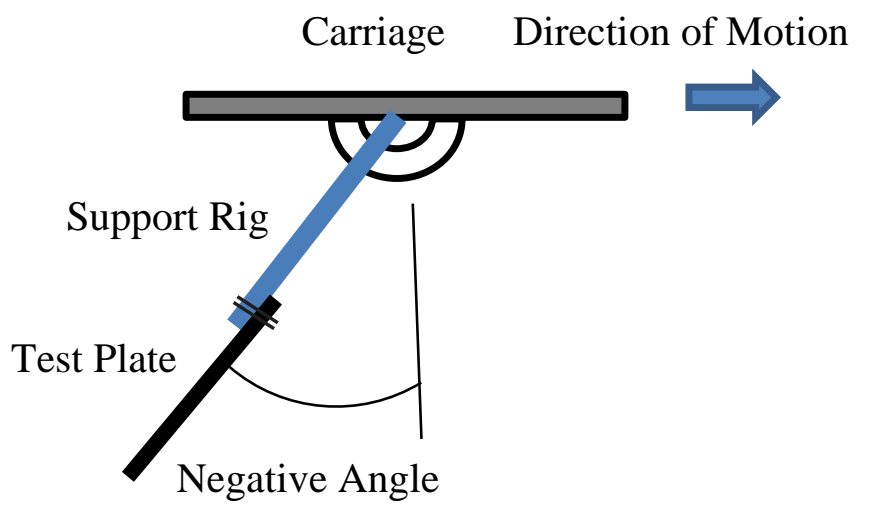

(a) Plate with negative angle

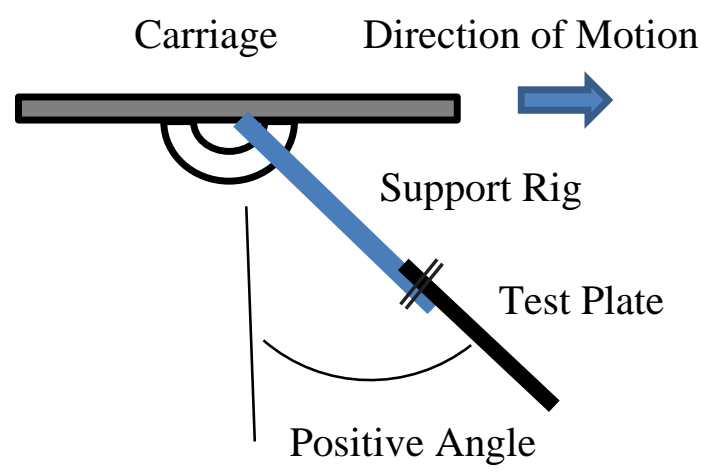

(b) Plate with positive angle

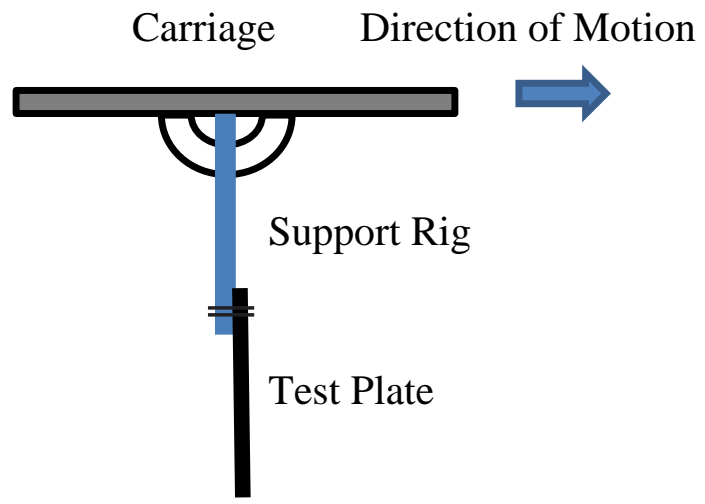

(c) Plate in vertical direction

Figure 1. Comparison of three different plate orientation angles relative to the direction of motion 


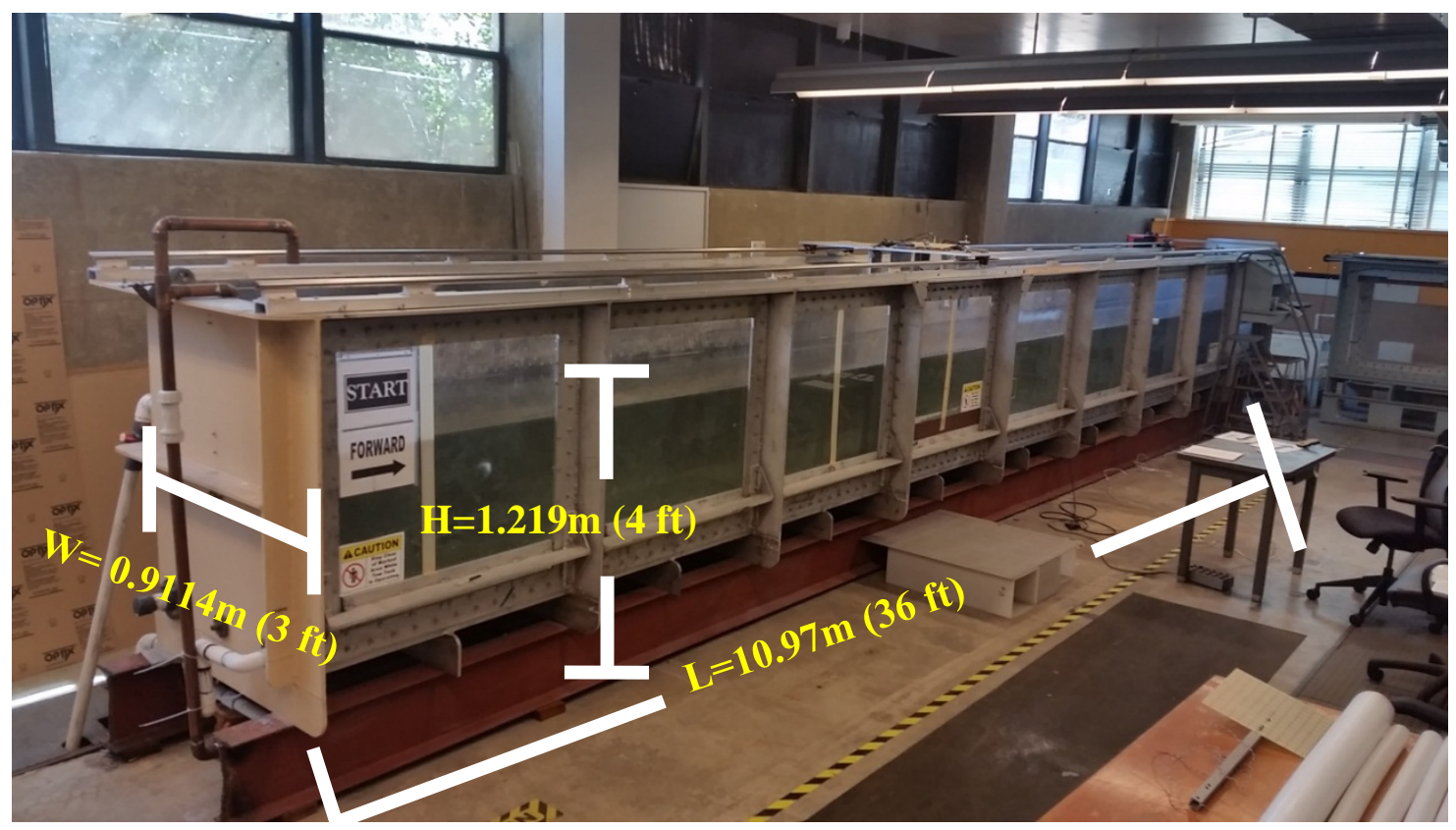

Figure 2. Tow tank with dimensions

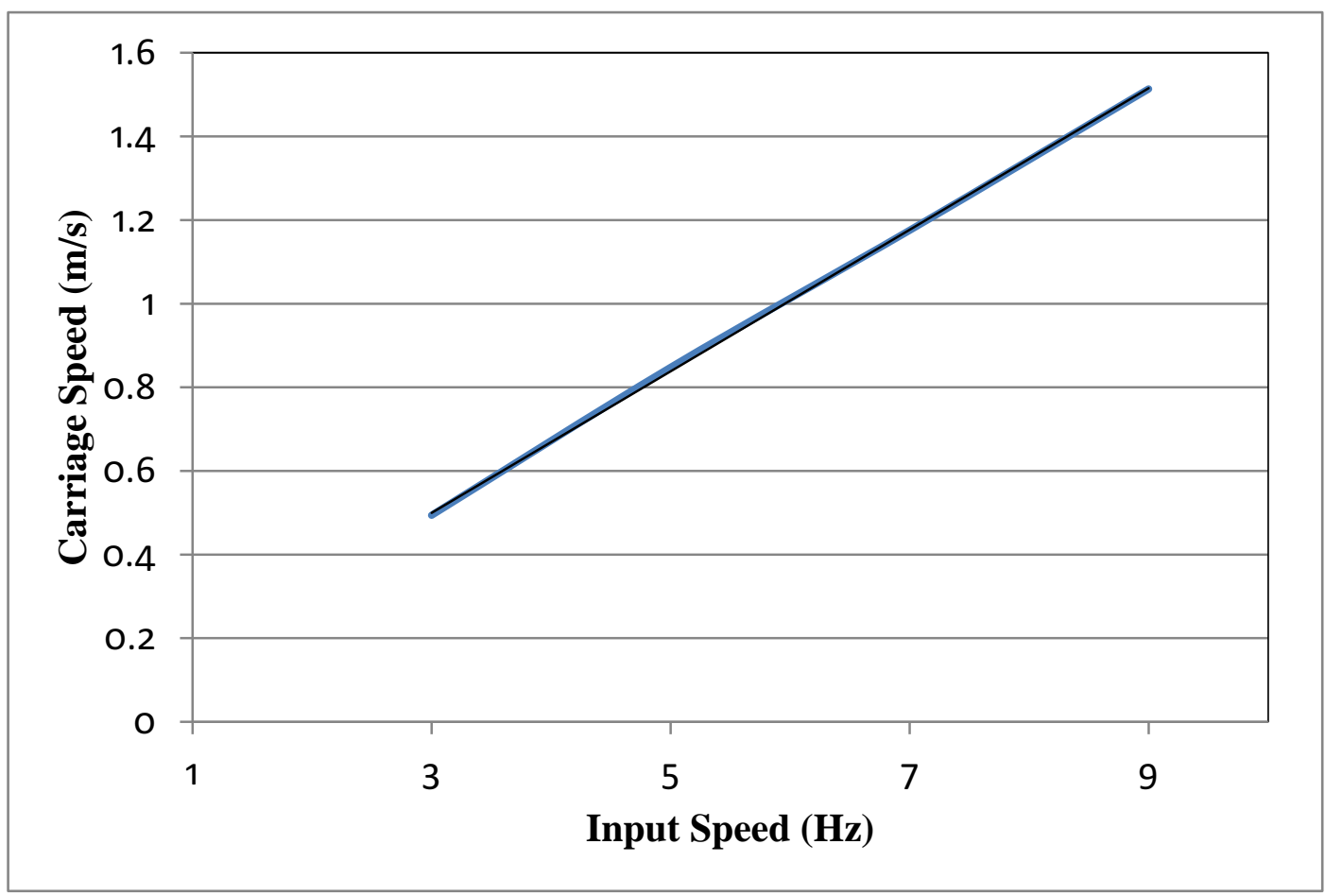

Figure 3. Correlation between speed setting $(\mathrm{Hz})$ and carriage velocity $(\mathrm{m} / \mathrm{s})$ 


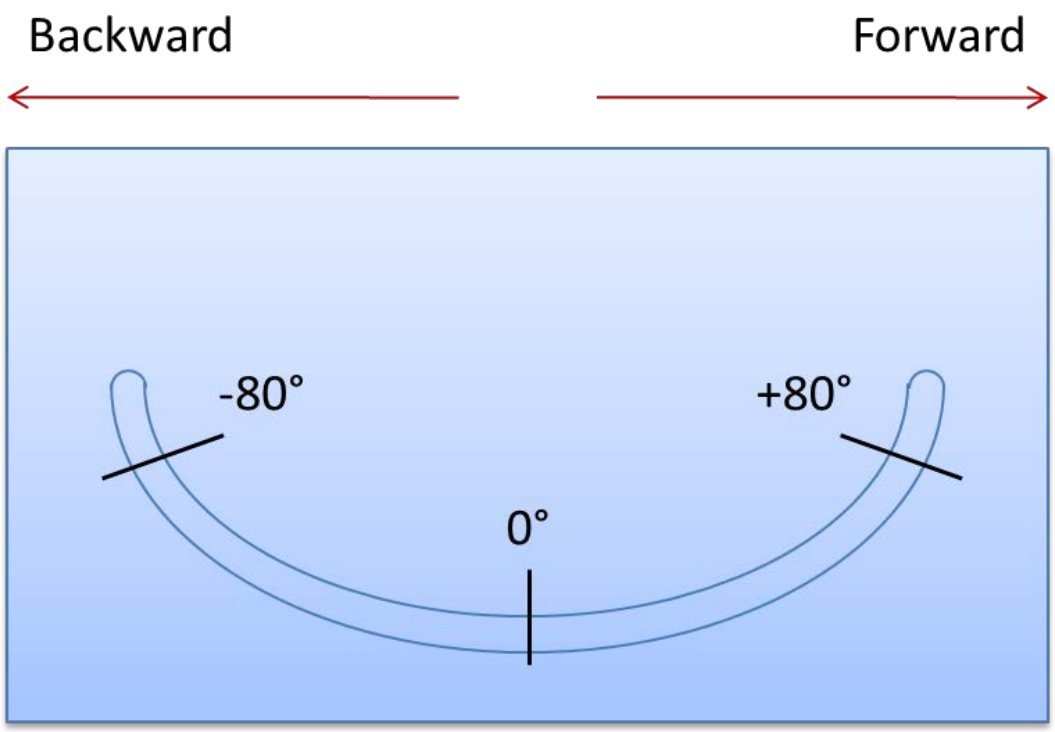

Figure 4. Angle selector for plate orientation

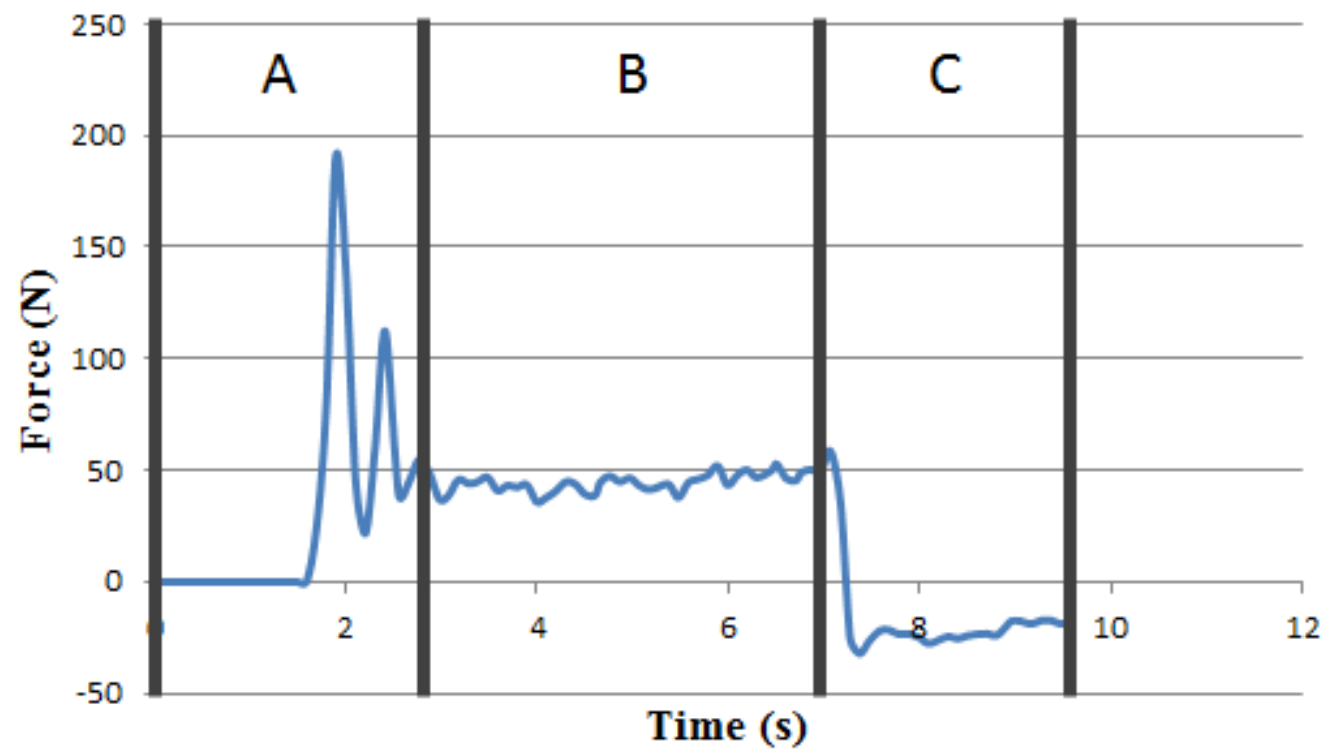

Figure 5. Data obtained from an experimental trial divided into (A) acceleration stage, (b) steady state stage, and (C) deceleration stage 


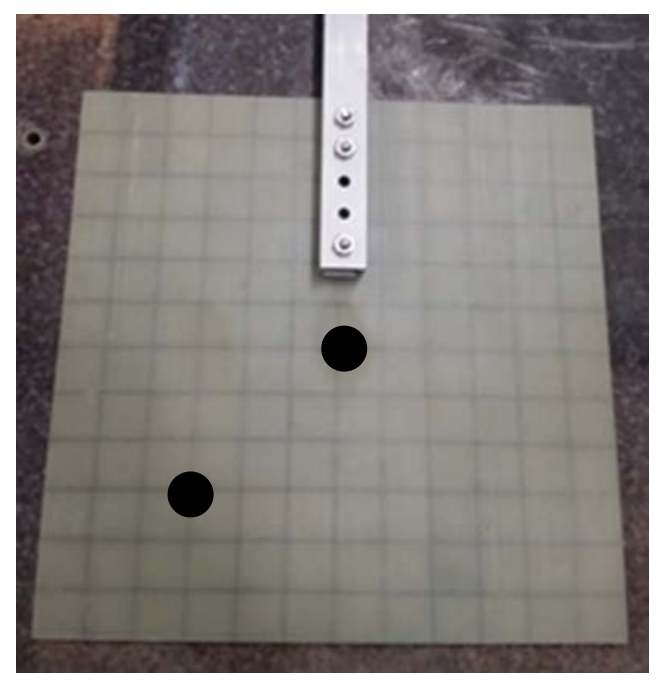

Figure 6. Composite Plates with free boundary

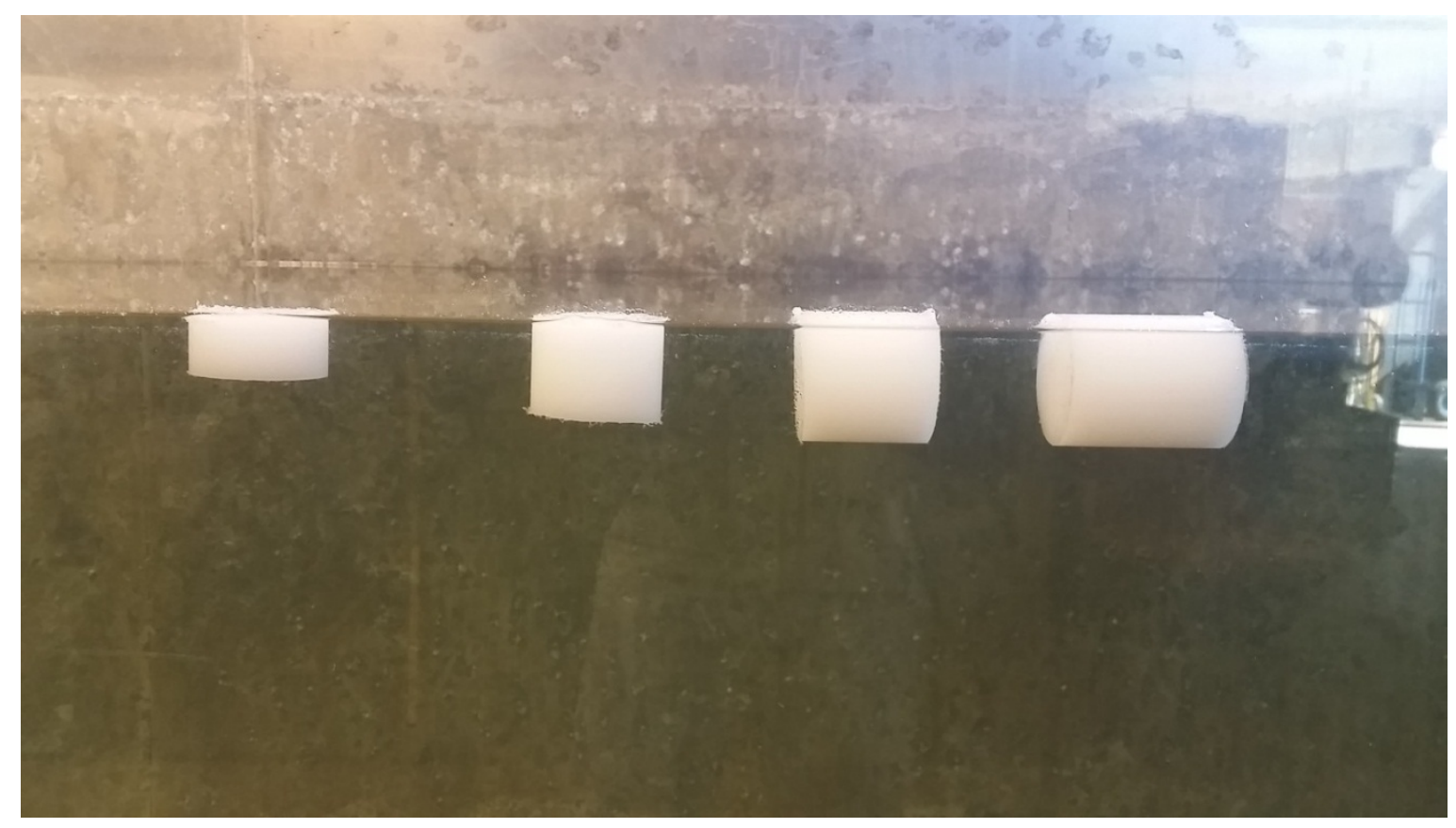

Figure 7. Floating characteristics of rods with different lengths $(25.4 \mathrm{~cm}, 38.1 \mathrm{~mm}$, $50.8 \mathrm{~mm}$, and $63.5 \mathrm{~mm}$, from left to right) 


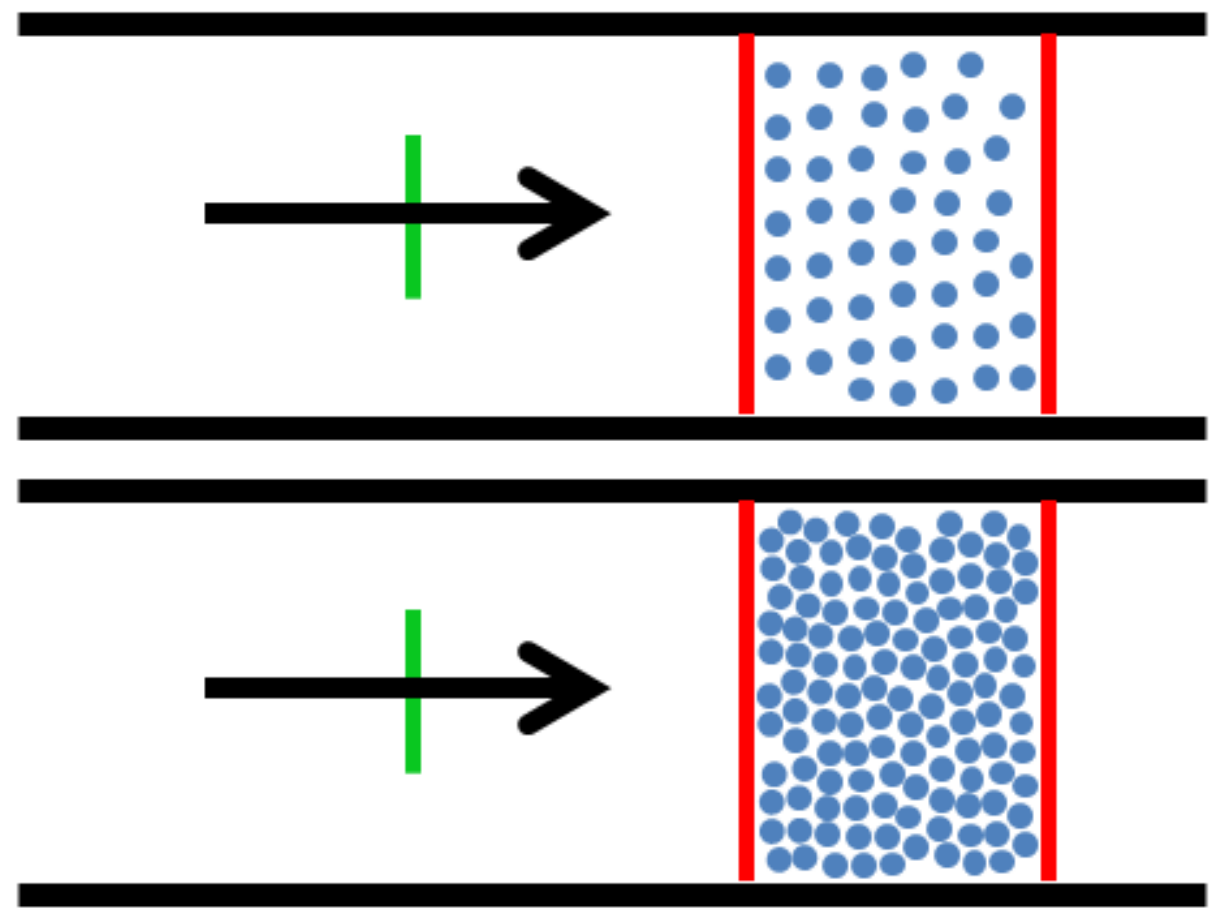

Figure 8. Experimental schematic comparing two different surface coverage ratios

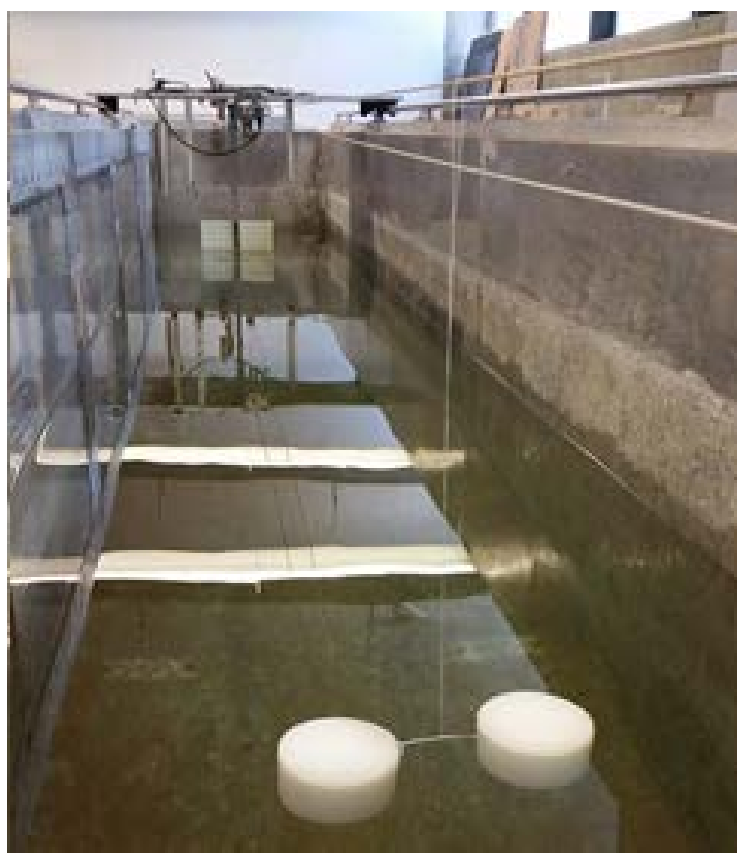

Figure 9. Large scale IEO impact test set-up. 


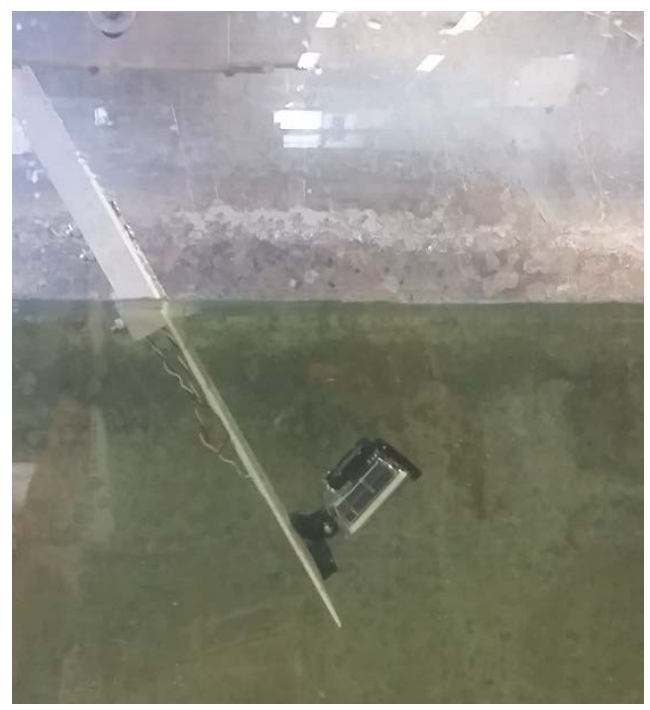

Figure 10. Underwater camera used to record underwater footage

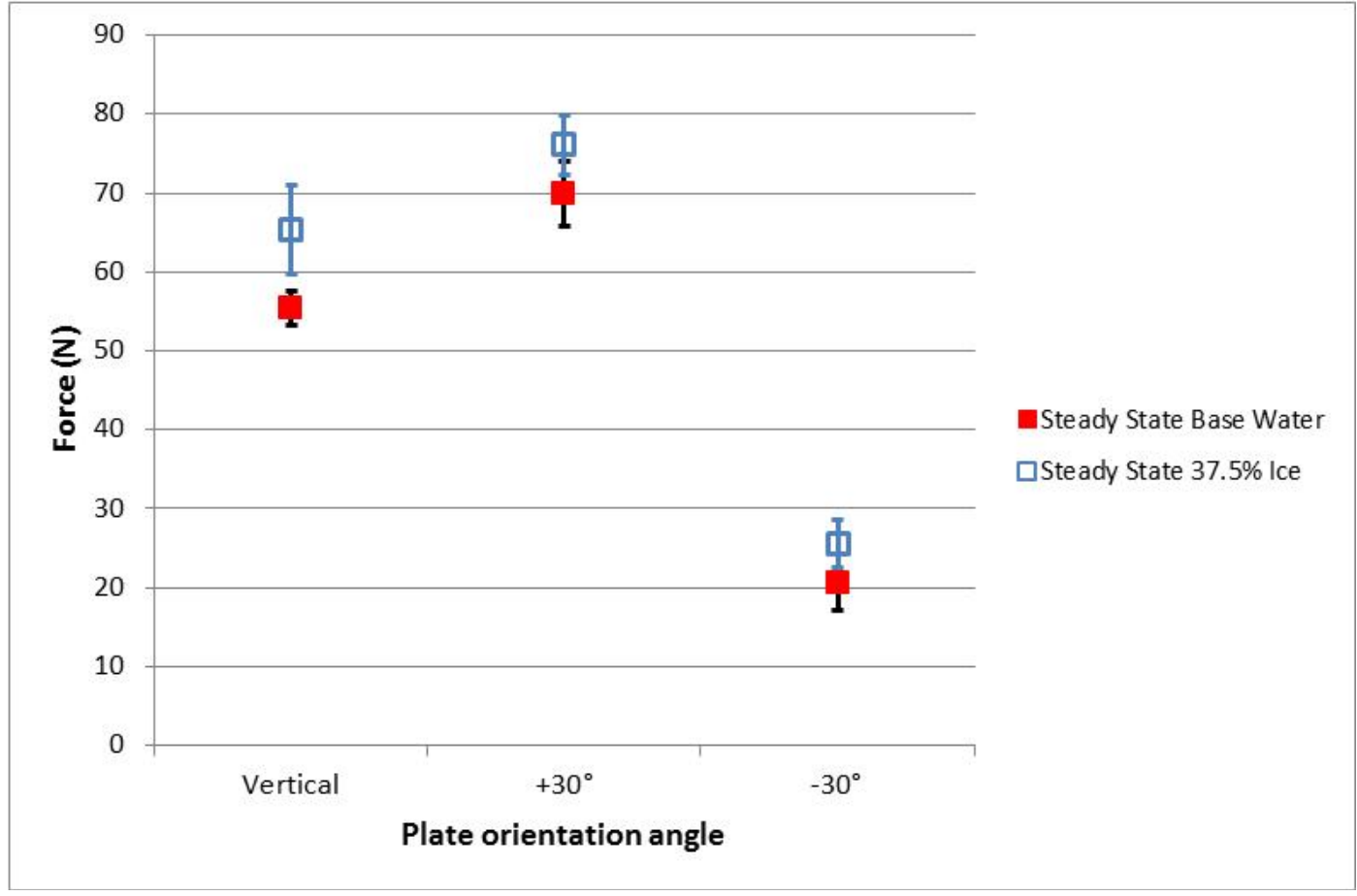

Figure 11. Drag force during steady-state motion of $1.50 \mathrm{~m} / \mathrm{s}$ at different plate orientations in water 


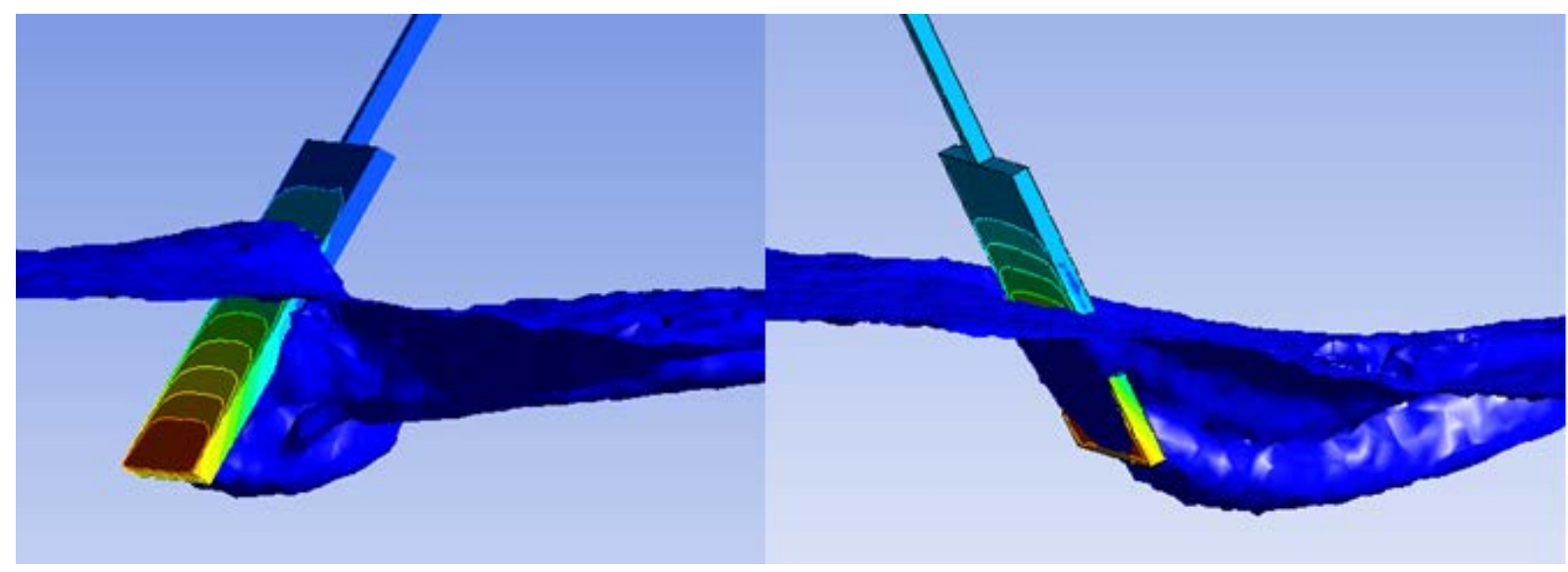

Figure 12. View of water level preceding the positive angled (Left) and negative angled (Right) plates.

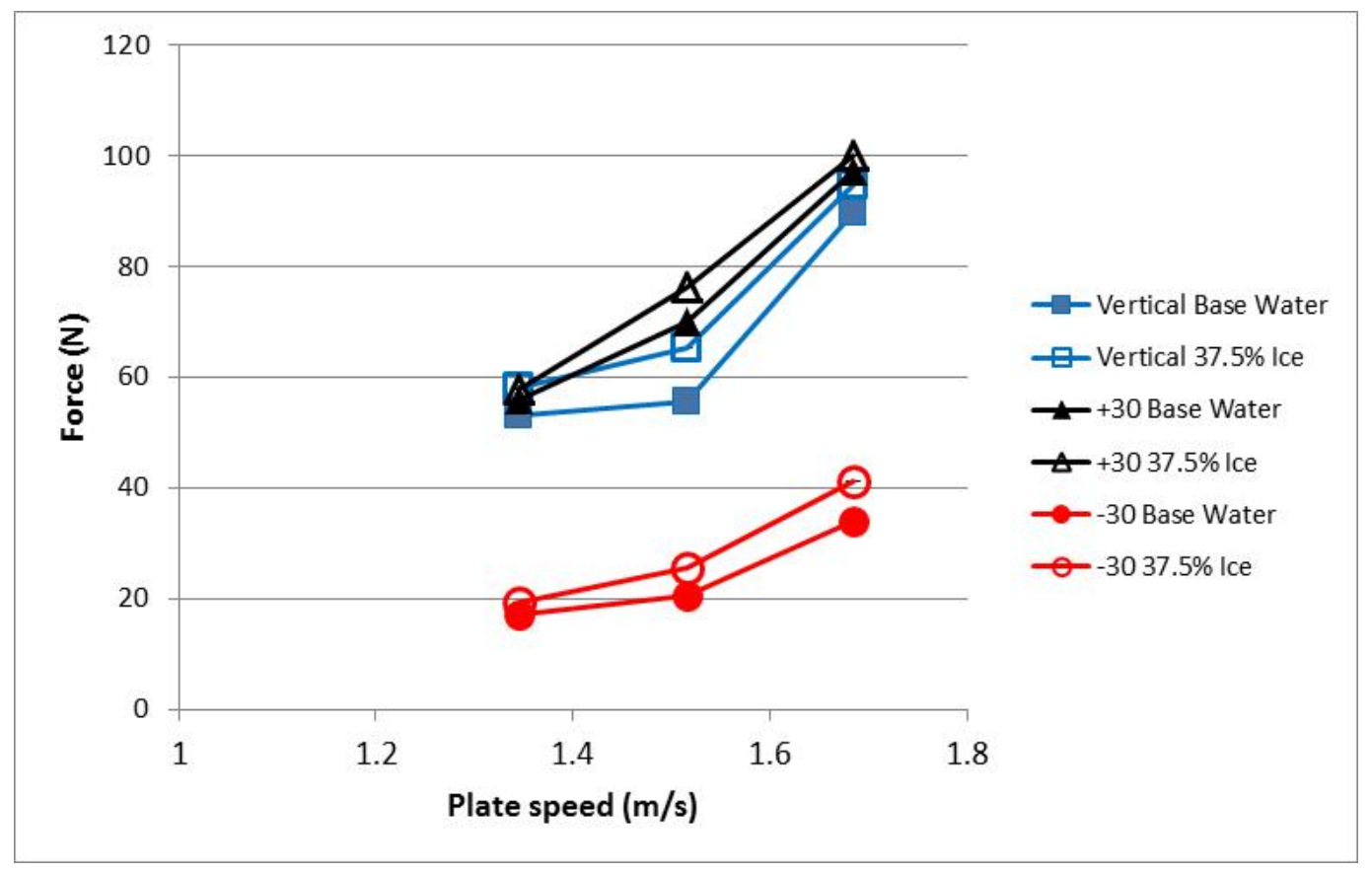

Figure 13. Drag force vs. steady-state speed for different plate orientation angles with and without ice equivalent objects 


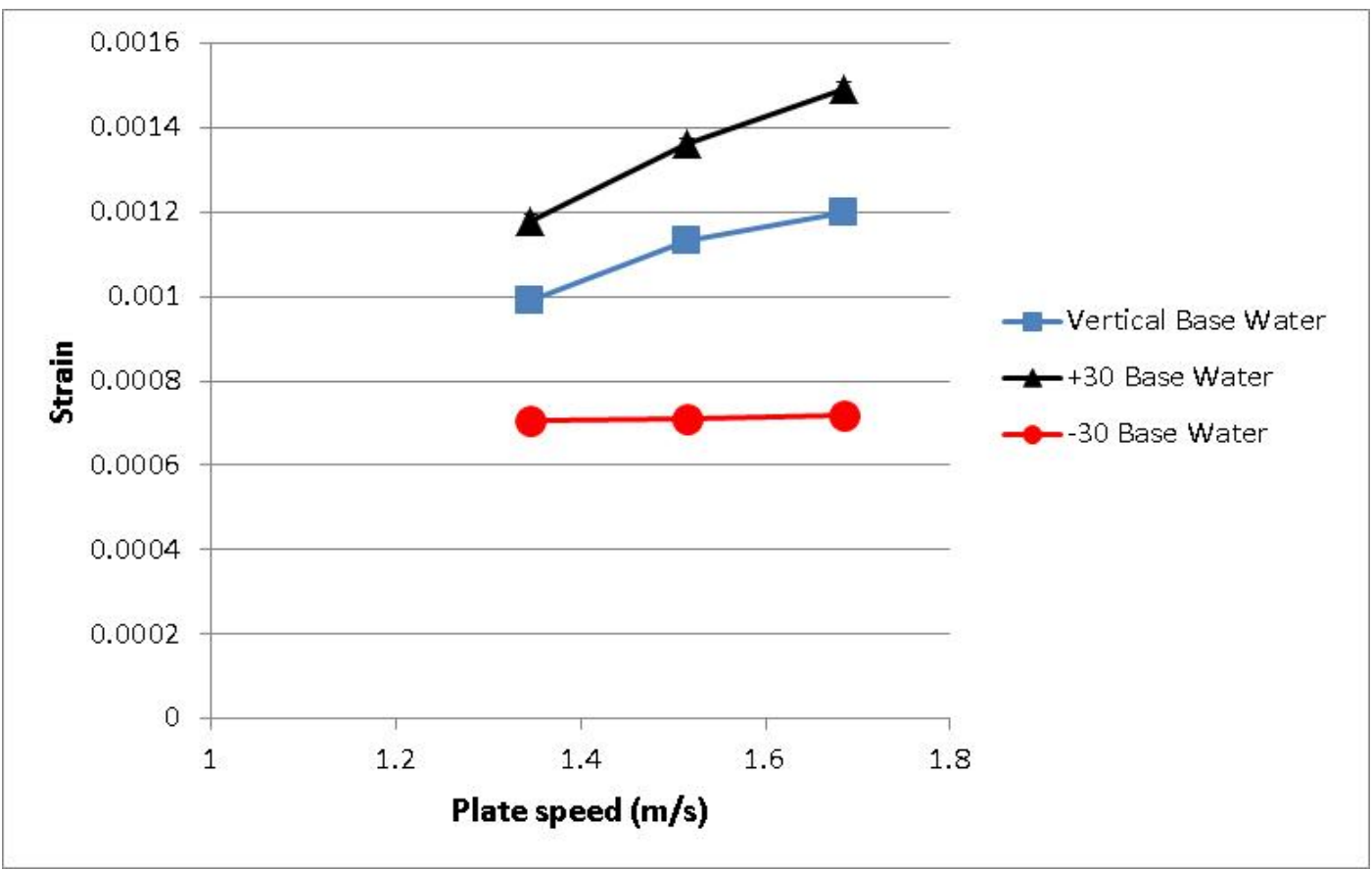

Figure 14. Vertical strains at the center of the plate at steady-state speeds for different plate orientation angles without equivalent objects

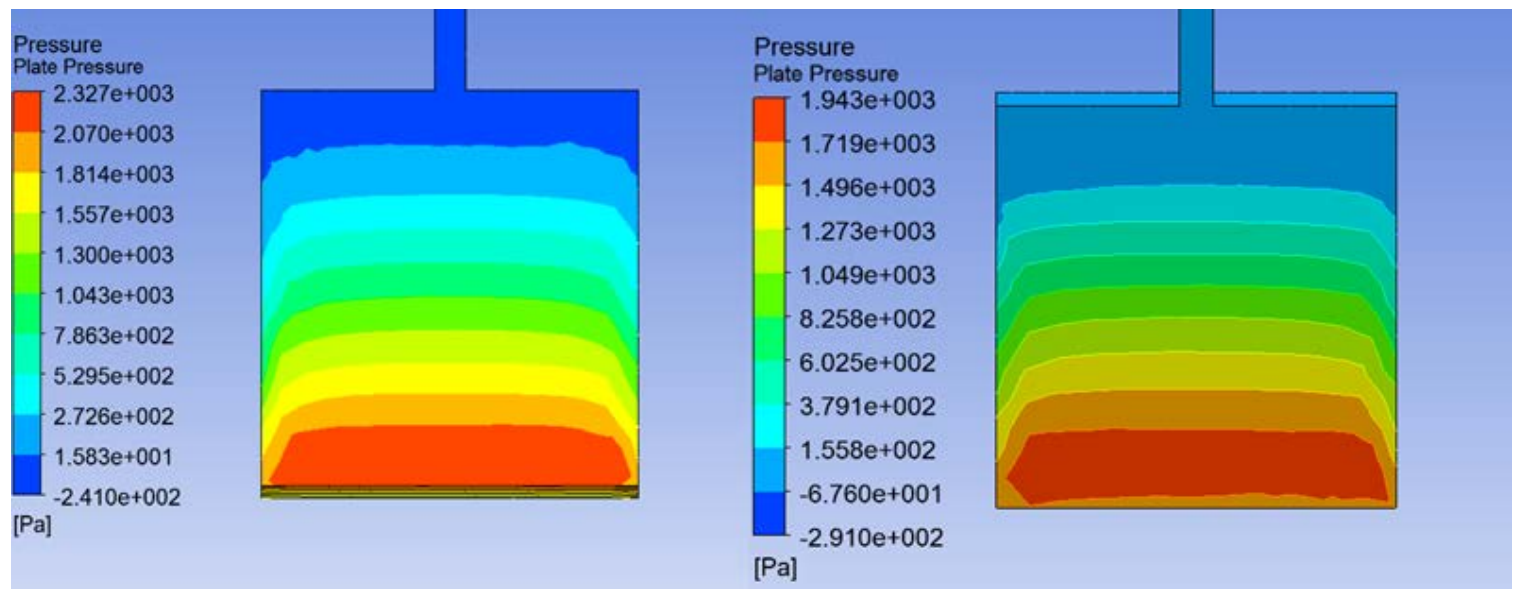

Figure 15. Incident pressure against the positively (Left) and negatively (Right) oriented plates 


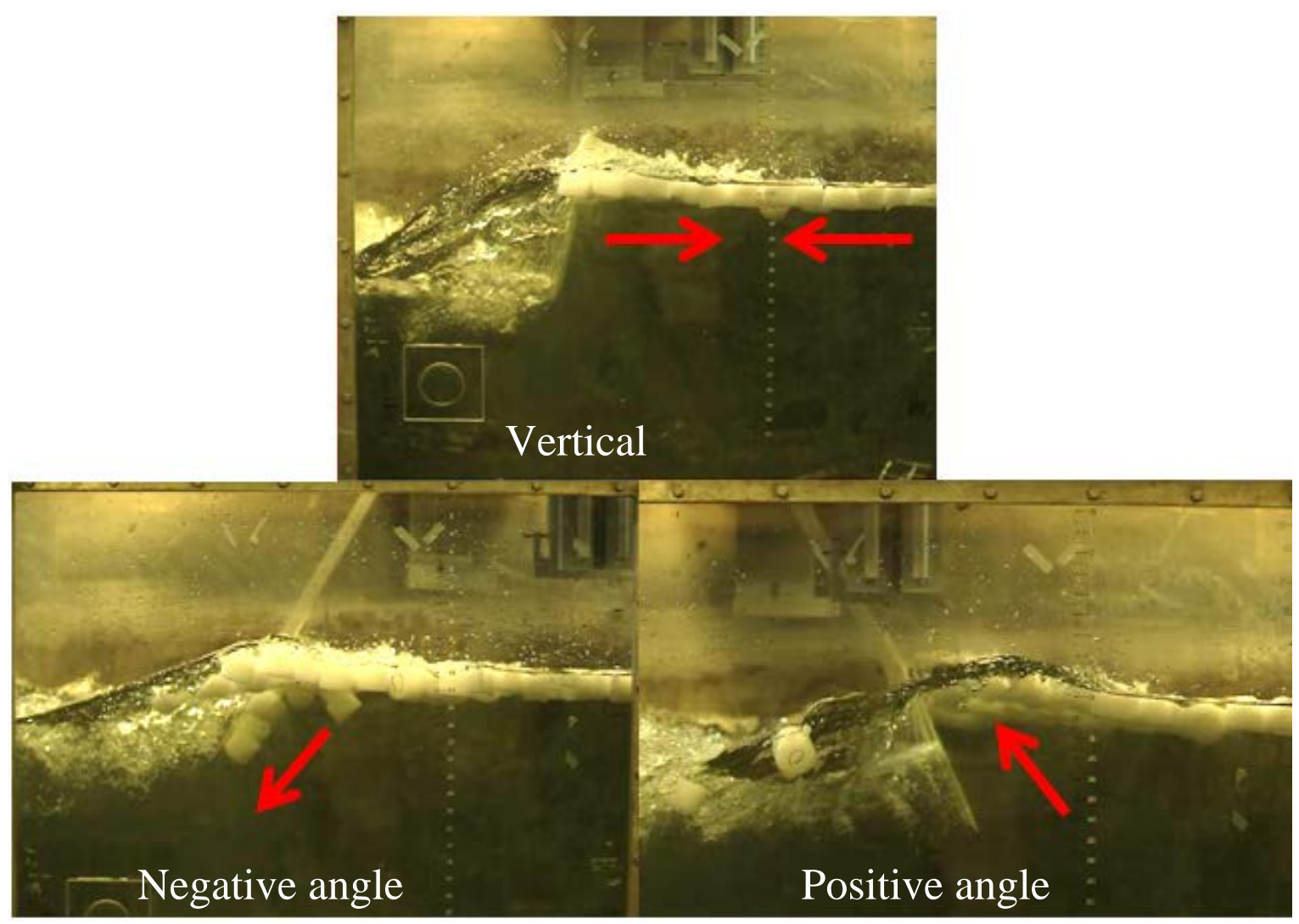

Figure 16. View of the small ice equivalent objects as the three plate orientations contact them (arrows indicate the direction of motion of the blocks.)

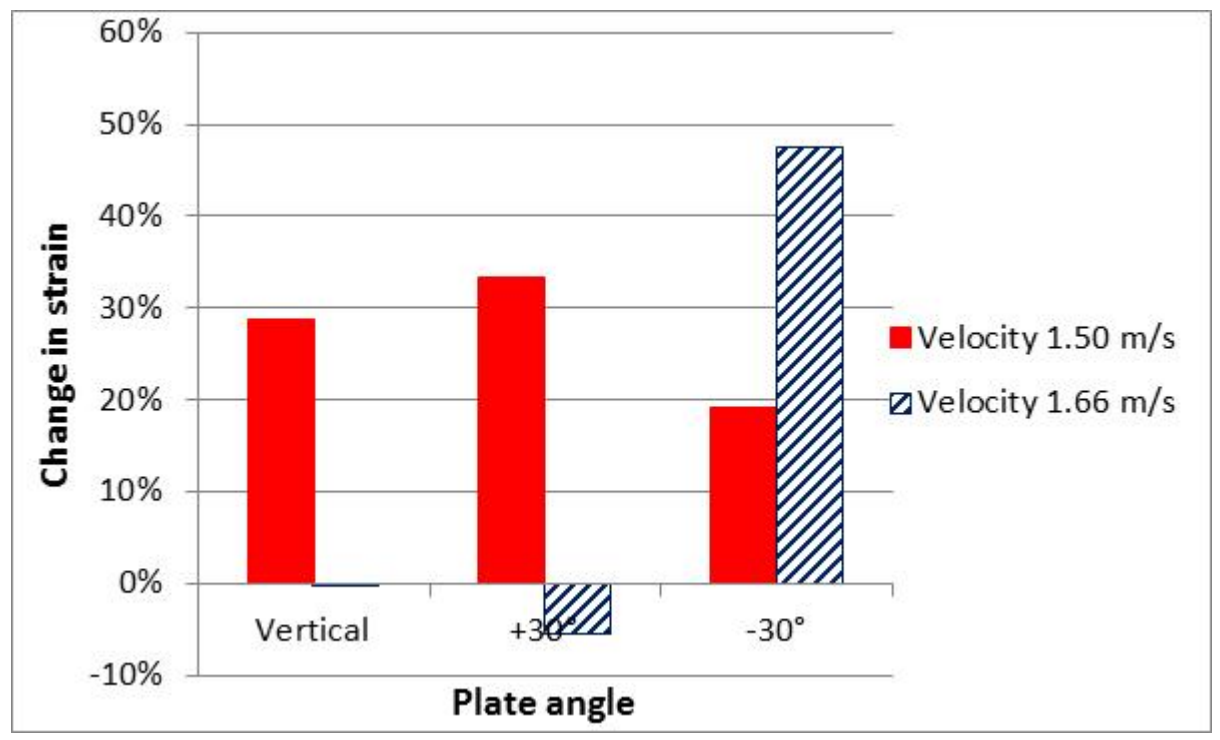

Figure 17. Change in horizontal bending strains at the quarter point location resulting from ice equivalent objects with steady-state motion 


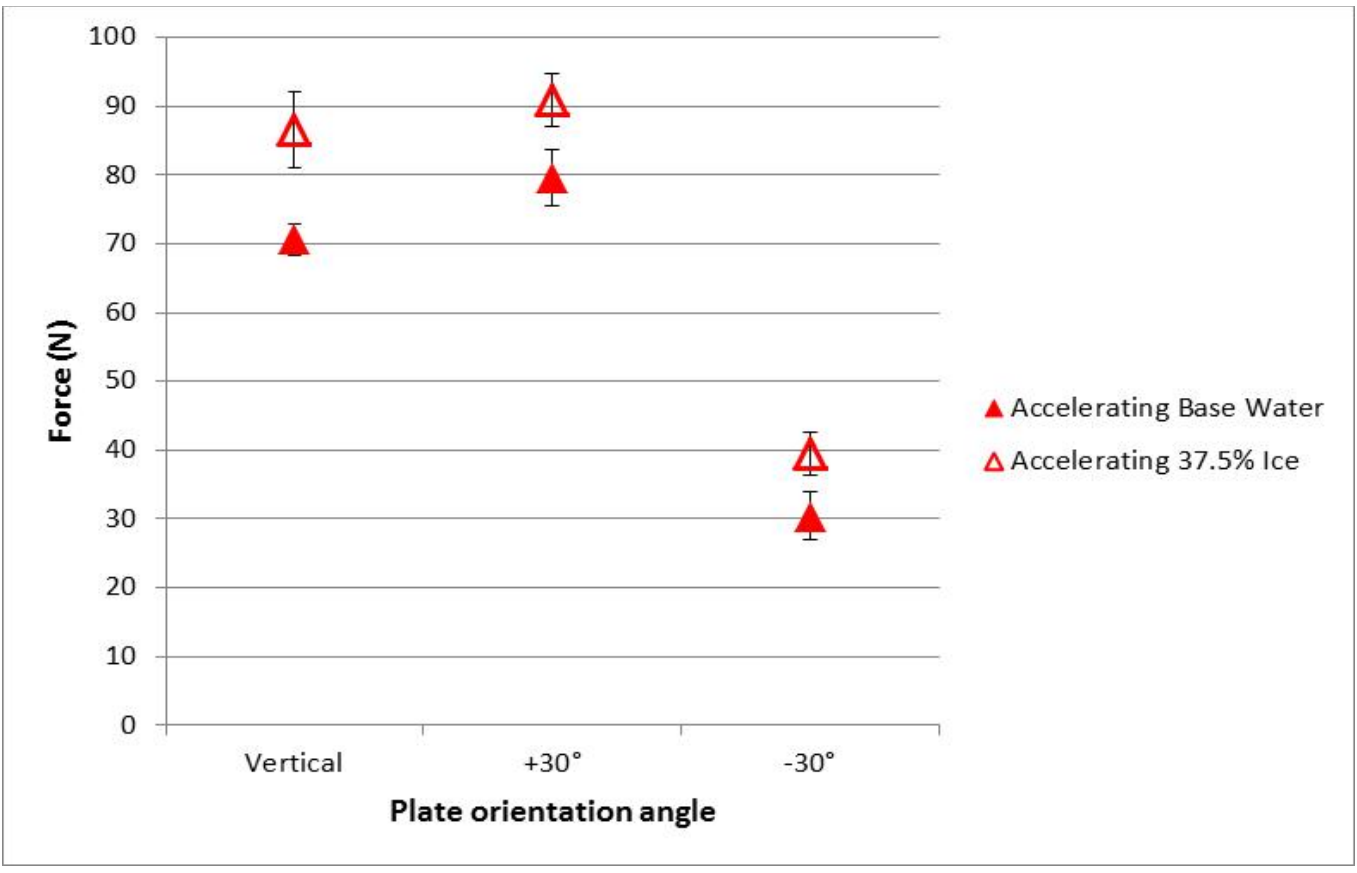

Figure 18. Drag force during accelerating motion at different plate orientations in water

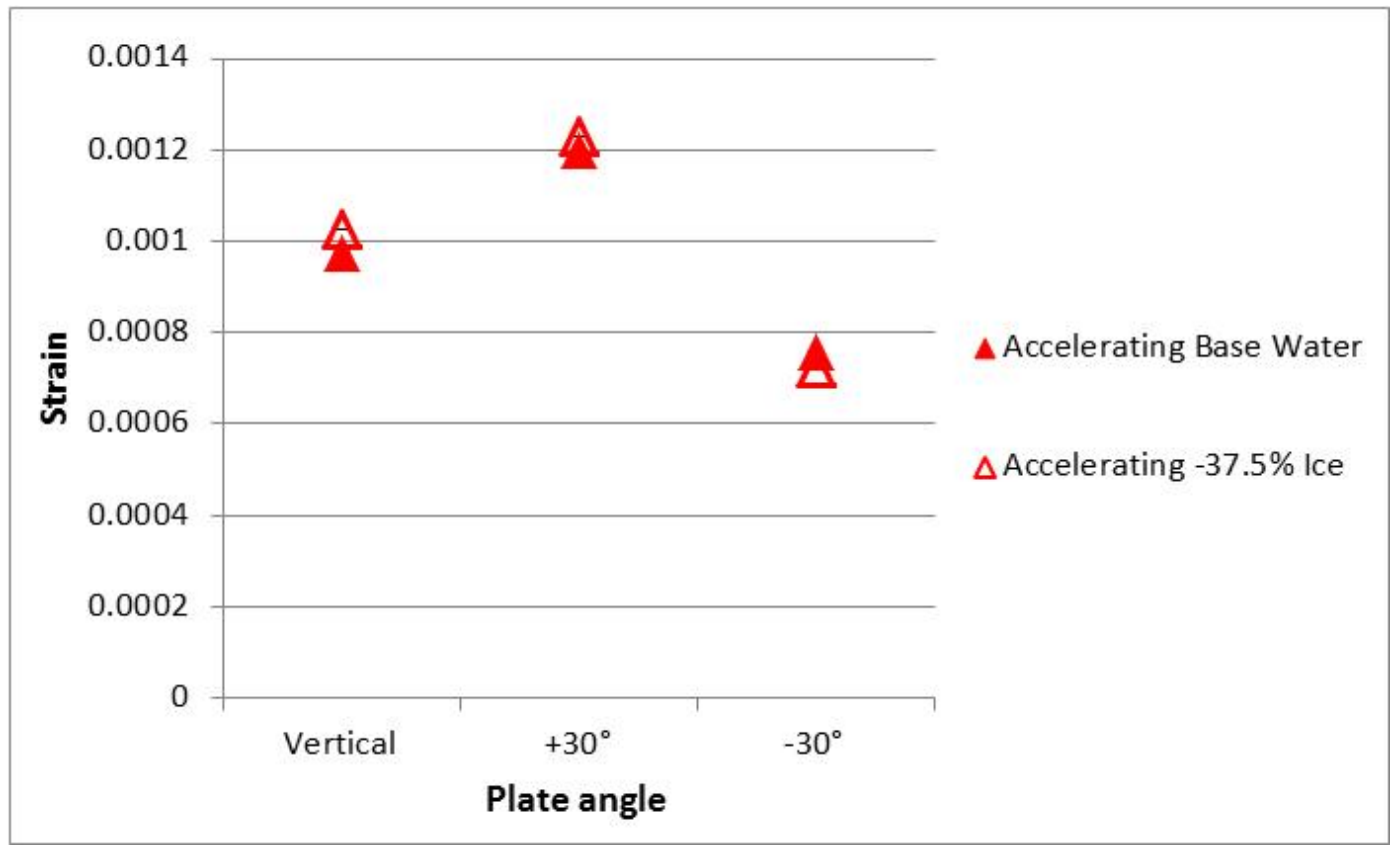

Figure 19. Vertical strains at the plate center during accelerating motion at different plate orientations in water 


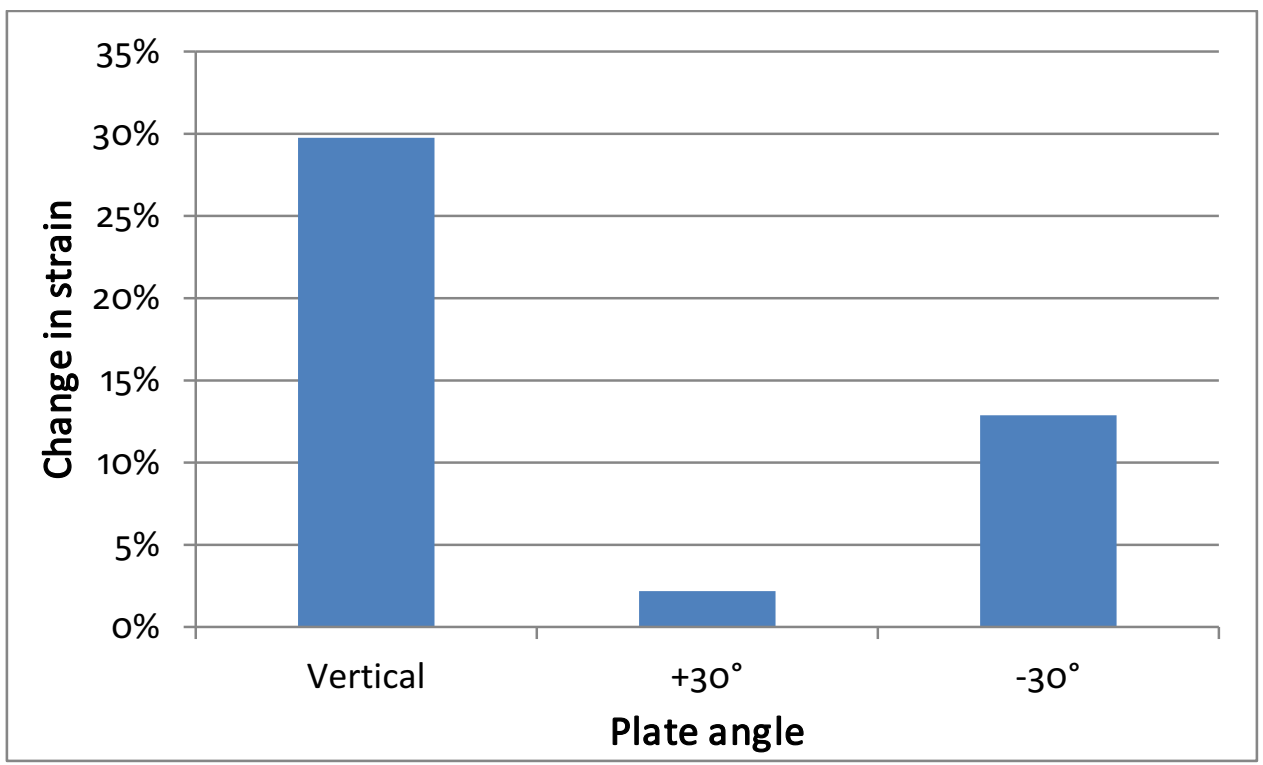

Figure 20. Horizontal strains at the plate quarter location during accelerating motion at different plate orientations in water 